\title{
Connexin hemichannels and cell death as measures of bovine COC vitrification success
}

\author{
Katarzyna Joanna Szymańska ${ }^{1}$, Nerea Ortiz-Escribano², Etienne Van den Abbeel $^{3}$, \\ Ann Van Soom ${ }^{2}$ and Luc Leybaert ${ }^{1}$ \\ ${ }^{1}$ Physiology Group, Department of Basic Medical Sciences, Ghent University, Ghent, Belgium, ${ }^{2}$ Reproduction, \\ Obstetrics and Herd Health, Ghent University, Merelbeke, Belgium and ${ }^{3}$ Center for Reproductive Medicine, \\ Ghent University Hospital, Ghent, Belgium \\ Correspondence should be addressed to K J Szymańska or L Leybaert; Email: katarzyna.jsv@gmail.com or luc.leybaert@ugent.be
}

\begin{abstract}
Vitrification of immature germinal vesicle-stage oocytes is a promising method in assisted reproduction but is associated with reduced developmental potential and low birth rates. Cumulus-oocyte complexes (COCs) express several connexins that form hexameric hemichannels, which interact head to head to create a gap junction or exist as unopposed free hemichannels. The latter are normally closed but open under stress conditions and may exert detrimental effects. We determined whether minimizing hemichannel opening and cell death during vitrification could improve COC quality. Bovine immature COCs underwent vitrification, storage and warming, followed by dye uptake to assess hemichannel opening and TUNEL staining to detect cell death. Based on these scores, we optimized the procedure by tuning the equilibration time, temperature, cryoprotectant concentration and extracellular $\mathrm{Ca}^{2+}$ concentration and assessed its impact on maturation, cleavage and blastocyst formation after parthenogenetic activation. We found that the major stressor resides in the cooling/warming phase of the vitrification procedure and observed that hemichannel opening and cell death in cumulus cells measure different aspects of cell stress. Optimization of the hemichannel and cell death readouts demonstrated that combined minimal hemichannel opening/cell death gave the highest cleavage rates but had no effect on maturation and blastocyst formation. Neither hemichannel nor cell death optimization performed better than the non-optimized protocol, leading to the conclusion that cell stress factors other than those detected by hemichannel dye uptake or TUNEL positivity are involved.

Reproduction (2019) 157 87-99
\end{abstract}

\section{Introduction}

The development of assisted reproductive technologies raised the need for accommodating cryopreservation techniques for gametes and embryos in animals and humans with vitrification being most commonly used. Cryopreservation by vitrification involves ultrarapid cooling without ice-crystal formation by plunging small sample volumes $(<1 \mu \mathrm{L})$ into liquid nitrogen $\left(\mathrm{LN}_{2}\right)$, followed by storage and, upon use, warming (Arav 2014). While vitrification is currently the best option available, it still compromises oocyte viability and induces cell damage. Strong physical changes of temperature and osmolarity as a result of high concentrations of cryoprotectants (CPs), and chemical stress caused by $\mathrm{pH}$ changes and $\mathrm{CP}$ toxicity collectively bring the cells far outside normal physiological conditions (Kopeika et al. 2015).

Contrary to MII-stage oocytes, immature oocytes can be retrieved at greater numbers without hormonal stimulation, which may trigger side effects like ovarian hyperstimulation syndrome (Brambillasca et al. 2013); moreover, they have their genetic material protected by the nuclear envelope. In animals, vitrification of immature oocytes facilitates the conservation of endangered species and recovery of female genetic material after the animal's death (Díez et al. 2012, Hwang \& Hochi 2014). In humans, immature oocytes offer a chance for patients that poorly respond to hormonal treatment, cannot undergo lengthy hormone stimulation because of therapeutic urgency or are at risk for stimulating hormone-sensitive tumors.

The immature germinal vesicle-stage (GV) oocyte maintains a direct, bidirectional gap junctional communication with the cumulus cells via transzonal projections until the oocyte reaches the mature MII stage (Anderson \& Albertini 1976, Kidder \& Vanderhyden 2010) Gap junctions are membrane channels composed of connexin (CX/GJA) proteins, named according to their molecular weight (Söhl \& Willecke 2003). Each CX has four transmembrane domain proteins, two extracellular loops, a cytoplasmic loop and cytoplasmic $\mathrm{C}$ - and $\mathrm{N}$ - terminal endings. Six CX (GJA) proteins form a hemichannel and the head-to-head interaction of 
two hemichannels from opposing cells, results in the formation of a gap junction channel, which connects the cytoplasm of the two cells in the most direct way possible (Evans \& Martin 2002). There are always single hemichannels present in the plasma membrane, existing as a pool underway to become gap junctions or as a pool with hemichannel faith only. Hemichannels are normally closed under physiological conditions but may open in response to various factors such as a decrease in extracellular $\mathrm{Ca}^{2+}$, an increase in intracellular $\mathrm{Ca}^{2+}$, strong depolarization of the membrane potential, ischemia, inflammation or mechanical stress (Wang et al. 2013, Orellana et al. 2014, Kim et al. 2016). When open, hemichannels create a large conductance and poorly selective leakage pore allowing the entry or the escape of essential ions and molecules up to $\sim 1.5 \mathrm{kDa}$, which may lead to cell damage and cell death (Decrock et al. 2009a, Retamal \& Sáez 2014). There are two main CX proteins in COCs that are crucial for folliculogenesis (Simon et al. 1997, Ackert et al. 2001): cumulus cells express CX43 (GJA1), which functionally connects these cells while the oocyte expresses CX37 (GJA4), which forms heterotypic CX37-CX43 gap junction channels with the cumulus cells at the level of the transzonal projections (Simon et al. 1997, Veitch et al. 2004).

Because human or primate material is not easy to obtain in quantities large enough for research, other animal models need to be considered. Unlike murine COCs that lose their cumulus cells during the vitrification procedure (Yamanaka et al. 2007), human and bovine COCs are less susceptible to disruption during handling, at least according to our experience. Apart from that, bovine oocyte size and the time required for oocyte growth and embryo development resemble the human (Ménézo \& Hérubel 2002, Santos et al. 2014). Vitrification of oocytes with an intact cumulus cell surrounding has been reported to improve maturation and developmental rates in mouse (Miyake et al. 1993, Nikseresht et al. 2015), horse (Tharasanit et al. 2009), sheep (Bogliolo et al. 2007), cow (Zhou et al. 2010) and human (Imoedemhe \& Sigue 1992). Moreover, interruption of gap junctional communication during COC vitrification may lead to compromised morphology and developmental competence (Hochi et al. 1996, VandeVoort et al. 2008, Luciano et al. 2009). While several studies have reported the consequences of disrupted gap junctions, very little is known about the impact of vitrification at the level of hemichannels. In a previous study, we reported that vitrification acted as a trigger for hemichannel opening in blastocyst cells and that inhibiting hemichannel opening with the CX-targeting peptide Gap26 significantly improved blastocyst hatching (Ortiz-Escribano et al. 2017). Here, we set out to determine the effect of vitrification on the immature GV-stage oocyte and surrounding cumulus cells on hemichannel opening and cell death. We hypothesized that minimizing hemichannel opening and cell death would improve oocyte maturation and subsequent development to the blastocyst stage. Our results demonstrate that vitrification by immersing COCs into $\mathrm{LN}_{2}$, followed by storage and subsequent warming are crucial steps that lead to hemichannel opening in cumulus cells while procedural COC manipulations or exposure to $\mathrm{CP}$-containing solutions by themselves had no effect. Minimizing hemichannel opening and cell death improved cleavage rate compared to minimizing cell death with residual hemichannel opening. Low combined scores of hemichannel opening and cell death are thus preferred to guide improvements of vitrification protocols.

\section{Materials and methods}

\section{Reagents and media}

Culture and handling media: HEPES-TALP (in mM) $\mathrm{NaCl}$ (114), $\mathrm{KCl}$ (3.1), $\mathrm{NaH}_{2} \mathrm{PO}_{4}(0.3), \mathrm{CaCl}_{2}(2.1), \mathrm{MgCl}_{2}(0.4), \mathrm{NaHCO}_{3}$ (2), sodium pyruvate (0.2), sodium lactate (10), HEPES (10) and further supplemented with $10 \mu \mathrm{g} / \mathrm{mL}$ gentamycin sulfate and $3 \mathrm{mg} / \mathrm{mL}$ bovine serum albumin (BSA). The final $\mathrm{pH}$ was set at 7.4; phosphate-buffered saline (PBS) and synthetic oviduct fluid ( $\mathrm{SOF}$, in $\mathrm{mM}$ ): myo-inositol (2.8), sodium citrate (0.3), $\mathrm{NaCl}$ (107.6), $\mathrm{KCl}(7.2), \mathrm{KH}_{2} \mathrm{PO}_{4}(1.2), \mathrm{MgSO}_{4} 5 \mathrm{H}_{2} \mathrm{O}$ (1.5), Na lactate (7.1), $\mathrm{NaHCO}_{3}$ (28.4), Na pyruvate (0.7), $\mathrm{CaCl}_{2} .2 \mathrm{H}_{2} \mathrm{O}(1.8)$, glutamine (0.4), and supplemented with $50 \mu \mathrm{g} / \mathrm{mL}$ gentamycine, $0.4 \%$ (W/v) BSA, $5 \mu \mathrm{g} / \mathrm{mL}$ insulin, $5 \mu \mathrm{g} / \mathrm{mL}$ transferrin, $5 \mathrm{ng} / \mathrm{mL}$ selenium (Ortiz-Escribano et al. 2017). Vitrification media: (1) Basic medium (BM) consisted of TCM199/Hanks/HEPES (Life Technologies Europe, Ghent, Belgium) supplemented with 20\% (v/v) FBS; (2) Equilibration Solution 1 (ES1): HM with 7.5\% (v/v) ethylene glycol (EG) and $7.5 \%(\mathrm{v} / \mathrm{v})$ DMSO and (3) Equilibration solution 2 (ES2): HM with $15 \%$ (v/v) EG, 15\% (v/v) DMSO and $0.5 \mathrm{M}$ sucrose. Warming media: (1) Warming Solution (WS) consisted of HM with $1 \mathrm{M}$ sucrose; (2) Dilution Solution 1 (DS1): HM with of $0.5 \mathrm{M}$ sucrose; and (3) Dilution Solution 2 (DS2): HM with of $0.25 \mathrm{M}$ sucrose. Low $\mathrm{Ca}^{2+}$ and zero $\mathrm{Ca}^{2+}$ media were prepared by addition of EGTA and subsequent correction of the $\mathrm{pH}$. The amount of EGTA was calculated with the Webmax Standard software: http://www.stanford.edu/ cpatton/webmaxcS.htm. Zero $\mathrm{Ca}^{2+}$ media contained $4 \mathrm{mM}$ EGTA and low $\mathrm{Ca}^{2+}$ media $\left(0.61 \mathrm{mM} \mathrm{Ca}^{2+}\right), 0.65 \mathrm{mM}$ EGTA. Gap26 composed of a 13 amino acid sequence on the first extracellular loop of CX43 (VCYDKSFPISHVR) was synthesized by Pepnome Limited (Jida Zhuhai, China) at $>90 \%$ purity.

All media, except the vitrification and warming media, were filtered through a sterile $0.22 \mu \mathrm{m}$ filter (Millipore Corporation) before use. Unless otherwise stated, all other components were obtained from Sigma.

\section{Collection of GV COCs}

The ovaries were collected from the slaughtered cattle and washed in warm physiological saline supplemented with kanamycin $(25 \mathrm{mg} / \mathrm{mL}$, GlBCO-BRL Life Technologies, Merelbeke, Belgium). COCs were recovered from follicles with 
a diameter of 2 to $8 \mathrm{~mm}$ using an 18 gauge needle attached to a $10 \mathrm{~mL}$ syringe. GV-stage oocytes with homogeneous dark cytoplasm and compact cumulus cells were selected and used in the experiments.

\section{In vitro maturation}

COCs were matured in groups of 70 in $500 \mu \mathrm{L}$ bicarbonatebuffered TCM199 medium (Life Technologies), supplemented with $50 \mathrm{mg} / \mathrm{mL}$ gentamycin and $20 \mathrm{ng} / \mathrm{mL}$ epidermal growth factor. Maturation was performed at $38.5^{\circ} \mathrm{C}$ in $5 \% \mathrm{CO}_{2}$ in humidified air for prolonged time of $26 \mathrm{~h}$, because we observed that after vitrification, oocytes needed more time for finalizing meiotic maturation. Each replicate, a part of the experimental group ( 20 oocytes from total of 70) was set aside for assessment of nuclear maturation, rest of the group ( 50 oocytes) were parthenogenetically activated. Nuclear maturation of oocytes was checked by $10 \mathrm{~min}$ staining with $10 \mu \mathrm{g} / \mathrm{mL}$ Hoechst 33342 (Life Technologies), after denudation and fixation in $4 \%$ PFA. Oocytes were mounted in 1,4-diazabicyclo (2.2.2) octane - DABCO medium and visualized on an inverted epifluorescence Nikon TE300 microscope with a 20x or $40 \times$ oil immersion objective and equipped with a DS-Ri1 camera (Nikon Benelux). Oocytes were classified as immature GV stage (presence of the nucleus), intermediate (germinal vesicle breakdown (GVBD) and metaphase I (MI)) or mature metaphase II (MII) characterized by the presence of genetic material organized in the chromosomes.

\section{Parthenogenetic activation and culture}

Matured oocytes were separated from the cumulus cells by 5 min vortexing in $\mathrm{HM}$ medium containing hyaluronidase $(1 \mathrm{mg} / \mathrm{mL})$ and then incubated $5 \mathrm{~min}$ in $5 \mu \mathrm{M}$ ionomycin, washed in HM medium and incubated in SOF medium with $2 \mathrm{mM}$ 6-dimethyl-aminopurine (6-DMAP) for $4 \mathrm{~h}$ (OrtizEscribano et al. 2016). After incubation, parthenotes were washed and cultured in groups of 25 in $50 \mu \mathrm{L}$ droplets in supplemented SOF medium with ITS $(5 \mu \mathrm{g} / \mathrm{mL}$ Insulin $+5 \mu \mathrm{g} /$ $\mathrm{mL}$ Transferrin $+5 \mathrm{ng} / \mathrm{mL}$ Selenium) and $0.4 \%$ BSA (Wydooghe et al. 2014) at $38.5^{\circ} \mathrm{C}$ in $5 \% \mathrm{CO}_{2}, 5 \% \mathrm{O}_{2}$ and $90 \% \mathrm{~N}_{2}$. Cleavage rates (the number of 2-cell stage embryos) were determined $45 \mathrm{~h}$ post activation, and blastocyst rates 8 days post activation.

\section{Vitrification protocol}

Immature COCs were vitrified and warmed with a slightly modified protocol published earlier (Stoop et al. 2012), see Fig. 1. Vitrification was performed stepwise at room temperature (RT, 22-26 ${ }^{\circ} \mathrm{C}$ ): two equilibration steps (STEP 1 and STEP 2), loading on a vitrification straw (STEP 3) and plunging in $\mathrm{LN}_{2}$, (STEP 4). For equilibration STEP 1, COCs were transferred to a $50 \mu \mathrm{L}$ droplet of BM solution for $1 \mathrm{~min}$. This droplet was then merged with an adjacent $50 \mu \mathrm{L}$ droplet of ES1 for 2 min; then, this droplet was again merged with a third $50 \mu \mathrm{L}$ ES1 droplet for 2 min. Next, oocytes were transferred to a fourth ES1 droplet for $10 \mathrm{~min}$. STEP 2 included sequential transfer to four $25 \mu \mathrm{L}$ droplets of ES2 solution, for $5 \mathrm{~s}, 5 \mathrm{~s}$ and $10 \mathrm{~s}$, respectively. The last droplet was used to load 8-9 COCs in the top of the gutter of the high-security vitrification (HSV) straw, at minimal volume $(<1 \mu \mathrm{L})-$ STEP 3 . The loading device was slid into the vitrification straw and sealed with a heating device. Finally, it was transferred to $\mathrm{LN}_{2}-\mathrm{STEP} 4$. After approximately $12 \mathrm{~h}$ of storage in $\mathrm{LN}_{2}$ (STEP 5), the upper part of the HVS straw was cut and the loading device was transferred quickly into a $39^{\circ} \mathrm{C}$ warm WS drop of $500 \mu \mathrm{L}-$ STEP 6. It was left on the warm plate for $1 \mathrm{~min}$. This was followed by a wash-out procedure at RT (STEP 7): $2 \times 2$ min in DS1 and $3 \times 3$ min in DS2, $50 \mu \mathrm{L}$ each. After this, COCs were washed and kept in BM (composition of the solutions, see Reagents and media).

\section{Immunofluorescence microscopy}

Freshly collected immature COCs were fixed in 4\% PFA, permeabilized with $0.1 \%$ Triton X-100 for $10 \mathrm{~min}$ and blocked with $1 \%$ BSA prepared in PBS for $1 \mathrm{~h}$. They were then incubated with primary antibody, either anti-CX43 polyclonal (1:500) or anti-CX37 polyclonal antibody (1:250) (Life Technologies Europe) diluted in blocking solution at $4{ }^{\circ} \mathrm{C}$ overnight. COCs were washed with PBS/BSA and incubated for $1 \mathrm{~h}$ at RT with the appropriate secondary antibody conjugated with Alexa-488 (1:500) (Life Technologies Europe). Finally, COCs were washed and counterstained with Hoechst. Some samples were additionally stained with rhodamine phalloidin, F-actin conjugated to the red-orange fluorescent dye tetramethylrhodamine (TRITC) (Life Technologies Europe) for $1 \mathrm{~h}$. COCs were mounted on slides. Images were obtained using a $20 \times(\mathrm{NA}=0.75)$ or a $63 \times$ water immersion $(\mathrm{NA}=1.2)$ objective on a Leica TCS-SP8 $X$ confocal microscope (Leica Microsystems).

\section{Hemichannel dye uptake studies}

We investigated the opening of hemichannels after vitrification and warming in immature COC cells by dye uptake assays with the hemichannel-permeable tracer propidium iodide (PI, 668 Da) and hemichannel-impermeable $10 \mathrm{kDa}$ dextranfluorescein (FITC) (Life Technologies Europe) described earlier (Ortiz-Escribano et al. 2017). After warming, COCs were incubated $25 \mathrm{~min}$ in a $50 \mu \mathrm{L}$ drop of PI solution $(1 \mathrm{mM}$ $\mathrm{PI}$ in HM) at RT. Because PI is also taken up by dead cells with ruptured plasma membranes, we added dextran-FITC $(200 \mu \mathrm{M})$ which cannot pass through hemichannels but readily enters the cell through disrupted membranes. We used Gap26 to inhibit hemichannels composed of CX43 and CX37 without affecting gap junctions when applied over a limited time period ( $1 \mathrm{~h}$ ) as previously demonstrated (Ortiz-Escribano et al. 2017). As a positive control, we used medium without divalent cations $\left(\mathrm{Ca}^{2+}\right.$ and $\left.\mathrm{Mg}^{2+}\right)$, which is a well-known stimulus for the opening of both CX43 and CX37 hemichannels (Li et al. 1996, Contreras et al. 2003, Puljung et al. 2004). Next, COCs were washed in $\mathrm{HM}$, fixed and counterstained with Hoechst. COCs were mounted on slides. Three images $10 \mu \mathrm{m}$ apart were taken of each COC using a $20 \times$ objective on a Leica TCS-SP8 X confocal microscope (Leica Microsystems). First, the total surface area stained by each dye was determined. The PI-positive area was expressed relative to the total area of nuclei stained with Hoechst. The dye-positive areas were 


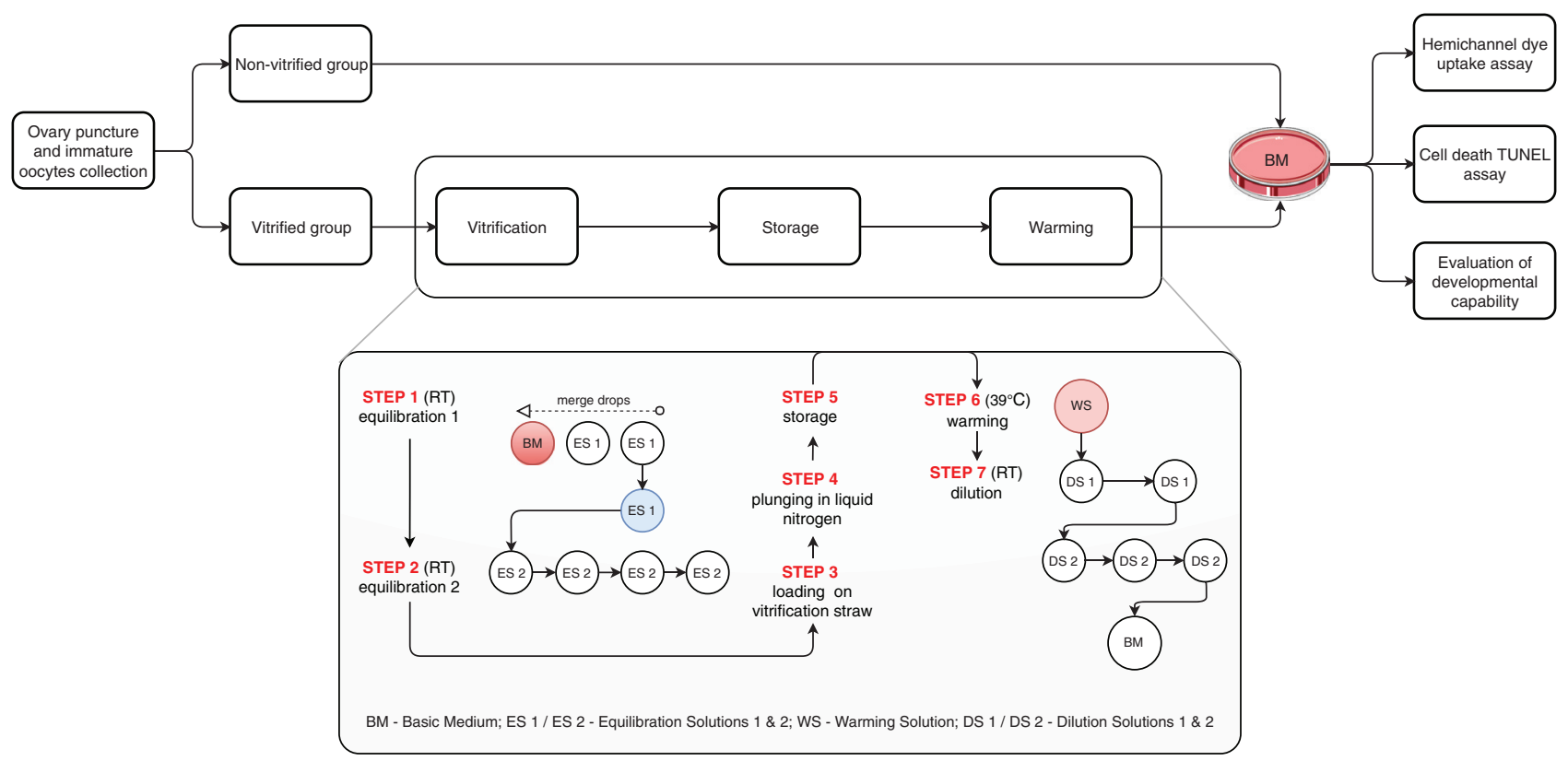

Figure 1 Overview of the experimental design and primary vitrification and warming protocol. Immature oocytes were collected from ovaries from the slaughterhouse. The non-vitrified control group was kept in the basic medium (BM) medium during the vitrification time, and then directly divided into groups: (1) hemichannel dye uptake assay, (2) cell death TUNEL assay or (3) for development test. For the latter, COCs were in vitro matured for $26 \mathrm{~h}$ and then parthenogenetically activated with $5 \mu \mathrm{M}$ ionomycin. Maturation was based on Hoechst staining, cleavage was assessed after $45 \mathrm{~h}$ of culture. Vitrified groups were vitrified, stored in liquid nitrogen $\left(\mathrm{LN}_{2}\right)$ and warmed. The process of vitrification and warming is described in detail in the gray shaded panel. The primary protocol consisted of two equilibration steps: for equilibration STEP 1, COCs were kept in a $50 \mu \mathrm{L}$ droplet of BM solution for $1 \mathrm{~min}$. This droplet was then merged with an adjacent $50 \mu \mathrm{L}$ droplet of ES 1 for 2 min; then again merged with a third $50 \mu \mathrm{L}$ ES 1 droplet for 2 min. Next, oocytes were transferred to a fourth ES 1 droplet for 10 min. During STEP 2 oocytes were sequentially transferred to three $25 \mu \mathrm{L}$ droplets of ES2 solution, for $5 \mathrm{~s}, 5 \mathrm{~s}$ and $10 \mathrm{~s}$, respectively. The fourth drop was used to load 8-9 COCs on the HSV straw - STEP 3. Then, oocytes were loaded on the straws (STEP 3), submerged in $\mathrm{LN}_{2}$ (STEP 4) and stored for $12 \mathrm{~h}$ (STEP 5). Warming consisted of transfer to a $500 \mu \mathrm{L}$ WS droplet of $39^{\circ} \mathrm{C}$ for $1 \mathrm{~min}$ (STEP 6) and subsequent washing in the $50 \mu \mathrm{L}$ droplets of decreasing sucrose concentrations: $2 \times 2 \mathrm{~min}$ in DS 1 and $3 \times 3 \mathrm{~min}$ in DS 2 (STEP 7). All the steps were performed at RT $\left(24-27^{\circ} \mathrm{C}\right)$ except the first droplet of the warming step $\left(39^{\circ} \mathrm{C}\right)$. After warming COCs were placed in the BM medium until all the oocytes from each group were thawed and then were divided into groups based on the performed experiment. The figure was created using Servier Medical ART.

quantified with FIJI Imagel after application of a threshold corresponding to the upper level of the background signal.

\section{Cell death TUNEL assay}

For quantification of cell death after vitrification and warming, immature COCs were fixed and then permeabilized as described in the previous section. Cell death was detected by TUNEL staining, using an in situ cell death detection kit in accordance with manufacturer's instructions (Roche, Belgium). The size of the TUNEL-positive area was expressed relative to the total area of nuclei stained with Hoechst per COC.

\section{Optimization of the vitrification protocol for minimal PI dye uptake and TUNEL staining}

We tested the effect of varying several parameters of the vitrification protocol and evaluated their influence on PI dye uptake as a proxy for hemichannel opening and on TUNEL positivity for cell death/apoptosis. Based on those results we performed a stepwise protocol optimization process during which the following parameters were optimized (Fig. 2): (i) the time of the equilibration step before vitrification (Fig. 1, last droplet of STEP 1), (ii) the temperature of the vitrification and warming steps, (iii) the concentration of the CPs used and (iv) the extracellular $\mathrm{Ca}^{2+}$ concentration. Finally, after vitrification and warming we tested the maturation, cleavage and blastocyst formation rates after parthenogenetic activation for all groups: the primary protocol and the two optimized protocols $\mathrm{A}$ and $\mathrm{B}$.

\section{Statistical analysis}

Data are expressed as mean \pm S.E.M., with ' $n$ ' denoting the number of COCs used in the experiment. Every experiment was repeated at least three times. Statistical analysis was done using GraphPad Instat (GraphPad Software). Bars of various conditions in the dye uptake and TUNEL experiments were compared by the Kruskal-Wallis test, a non-parametric ANOVA-based method. Binomial variables obtained from the maturation, cleavage and blastocyst formation experiments were analyzed using a binary logistic regression model. The level of statistical significance was set at $P<0.05$. 


\section{Stepwise guide through protocol optimization process}

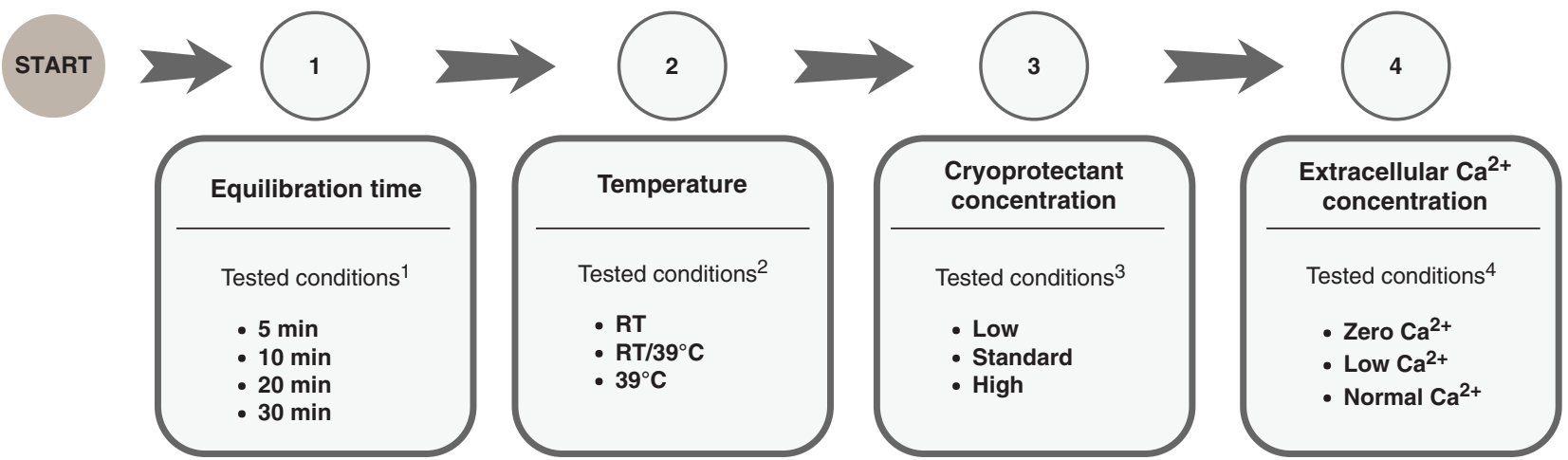

Figure 2 Stepwise guide through protocol optimization process. ${ }^{1}$ Time in the last drop of equilibration $1-\mathrm{STEP} 1 .{ }^{2} \mathrm{RT}-\mathrm{RT}$ during the whole procedure; RT $/ 39^{\circ} \mathrm{C}-\mathrm{RT}$ throughout except 1 st drop of warming step; $39^{\circ} \mathrm{C}-39^{\circ} \mathrm{C}$ during the whole procedure. ${ }^{3} \mathrm{Low}$ : $5 \% \mathrm{DMSO} / 5 \% \mathrm{EG}$ in STEP $1 ; 7.5 \%$ DMSO/7.5\% EG in STEP 2; Standard: 7.5\% DMSO/7.5\% EG in STEP 1; 15\% DMSO/15\% EG in STEP 2; High: 10\% DMSO/10\% EG in STEP $1 ; 20 \%$ DMSO/20\% EG in STEP $2 .{ }^{4}$ Zero $\mathrm{Ca}^{2+}: 4 \mathrm{mM}$ EGTA added to the $\mathrm{Ca}^{2+}$ containing solution; Low $\mathrm{Ca}^{2+}: 0.65 \mathrm{mM}$ EGTA added to the $\mathrm{Ca}^{2+}$ containing solution, giving $0.61 \mathrm{mM}$ free $\mathrm{Ca}^{2+}$; Normal $1.26 \mathrm{mM} \mathrm{Ca}^{2+}$.

\section{Results}

\section{Connexin expression in bovine COCs}

Immunostaining analysis confirmed the presence of both CX43 and CX37 in immature COCs (Fig. 3). CX43 expression was found in cumulus cells, whereas CX37 was localized in the oocyte, in line with data on mice and humans (Simon et al. 1997, Wang et al. 2009). Both CX43 and CX37 were present in transzonal projections that traverse the zona pellucida and connect the cumulus cells with the oocyte as heterotypic gap junction channels formed by the two CX isotypes (Kidder \& Mhawi 2002).

\section{Dye uptake studies in COCs indicate hemichannel opening in response to vitrification}

We investigated whether the vitrification process triggers hemichannel opening in immature COC cells (Fig. 1 shows experimental design). We used Gap26
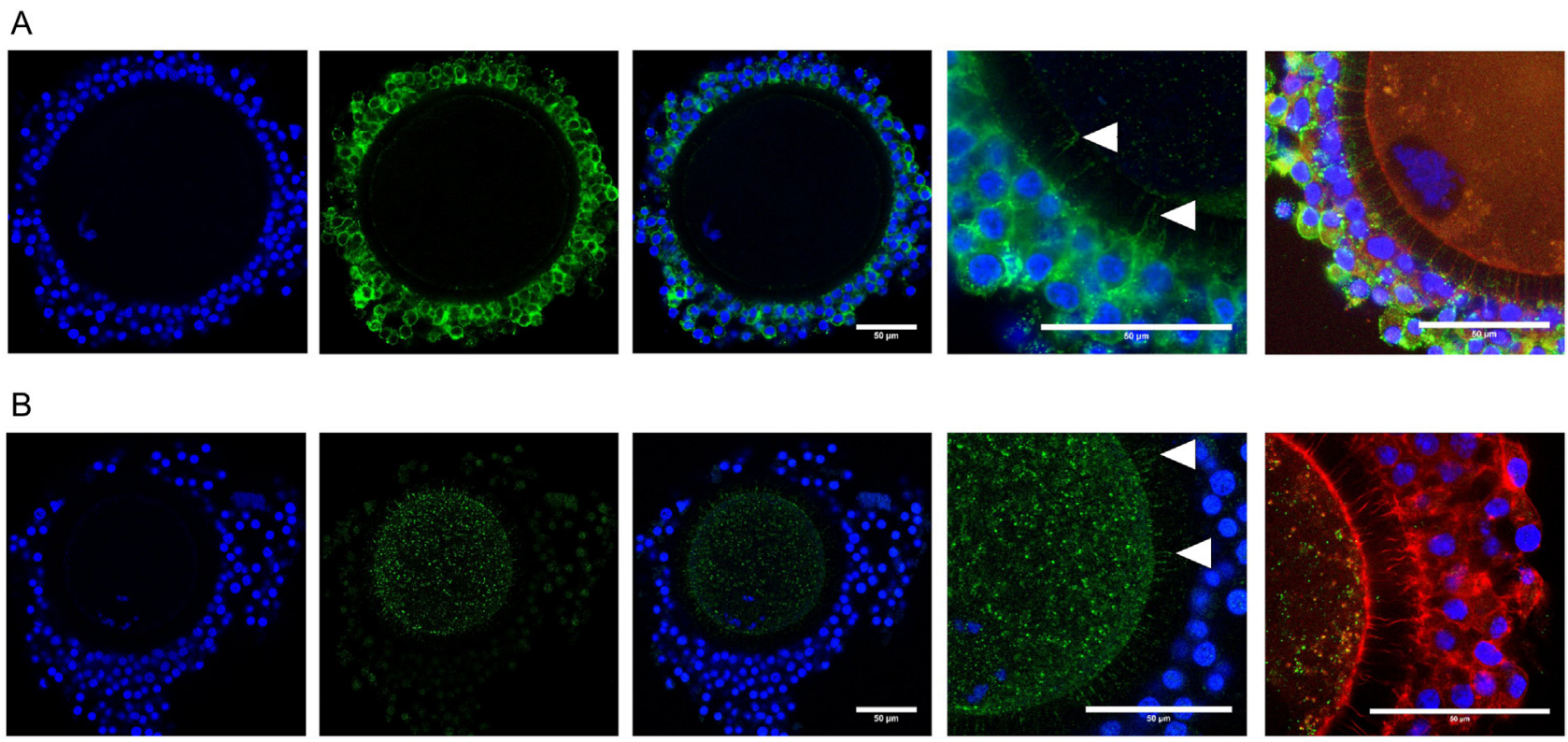

Figure 3 Localization of CX43 in the membrane of cumulus cells and CX37 in oocytes. (A and B) Confocal images show the presence of CX43 (A) and CX37 (B) in bovine COCs in green. Both connexins are present in transzonal projections and are indicated by white arrows. Blue represents nuclear Hoechst staining and red shows transzonal projections by F-actin staining with phalloidin-rhodamine. Scale bar measures $50 \mu \mathrm{m}$. 
$(200 \mu \mathrm{M})$ to inhibit hemichannel opening without affecting gap junctions; the peptide was added to the solutions of vitrification STEP 2, just before loading on the vitrification straw, such that it was present during $\mathrm{LN}_{2}$ immersion (steps are defined in Fig. 1) as well as the warming (STEP 6) and dilution (STEP 7) steps. $\mathrm{Ca}^{2+}$ and $\mathrm{Mg}^{2+}$-free medium, which triggers hemichannel opening, was used as positive control. As shown in Fig. 4A, vitrification significantly increased the percentage of Pl-positive cells compared to the nonvitrified control and this was significantly inhibited by Gap26, indicating dye uptake occurred through CX hemichannels. Importantly, PI-positive cells were always cumulus cells, never oocytes. The number of cumulus cells positive for dextran-FITC $(10 \mathrm{kDa})$, which does not permeate through hemichannels, was always below $0.5 \%$, pointing to no major disturbance of the plasma membrane or low levels of other large pores that would allow the passage of a $10 \mathrm{kDa}$ tracer. Oocytes were never positive for dextran-FITC. Taken together, these results indicate that PI uptake in cumulus cells triggered by vitrification occurred through hemichannels, most likely composed of CX43.

\section{Hemichannel opening does not occur in response to vitrification solutions and cell manipulation in the absence of $L N_{2}$ cooling and warming}

We further tested whether the solutions and the associated cell manipulations on their own or in combination with $\mathrm{LN}_{2}$ cooling and subsequent warming could trigger hemichannel opening. A first group was exposed to the STEP 1-associated ES1 solution (Fig. 1) at RT, followed by the PI dye uptake assay. A second group was exposed
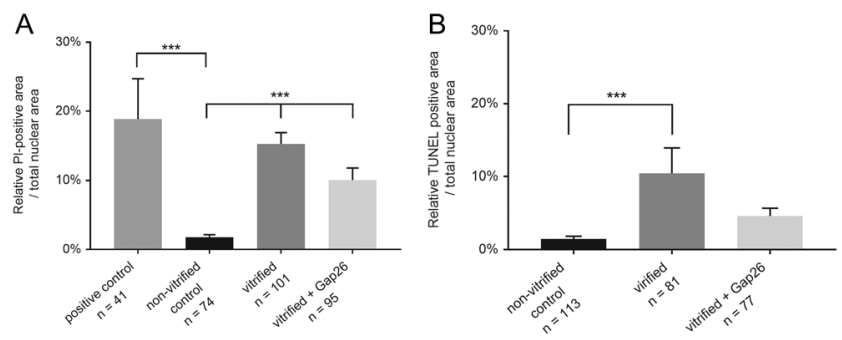

Figure 4 Vitrification triggers hemichannel opening measured with $\mathrm{PI}$ dye uptake (A) and apoptotic cell death, measured by TUNEL staining (B) in COCs. COCs were vitrified and warmed with or without peptide Gap26 and afterward, either PI dye uptake assay or TUNEL staining were performed. (A) Gap26 significantly blocked PI uptake triggered by vitrification. The positive control group was exposed to medium without $\mathrm{Ca}^{2+}$ and $\mathrm{Mg}^{2+}$. Oocytes were never Pl-positive. (B) Cryopreservation significantly increased the number of TUNELpositive cells which is only partially inhibited by Gap26. Oocytes were never TUNEL positive. The graphs illustrate summary data of the percentage of the PI-positive cell area or TUNEL-positive area relative to the total nuclei (Hoechst) area per COC. All data are presented as mean \pm S.E.M., results were analyzed with a non-parametric ANOVA, Kruskal-Wallis test; $* * * P<0.001$. to the STEP 1 solution (ES1) followed by transfer to the STEP 2 solution (ES2). A third group was exposed to all steps and associated solutions, except the $\mathrm{LN}_{2}$ cooling of STEP 4 and the storage of STEP 5 . As a fourth condition, COCs were exposed to the full procedure including all steps; in these experiments, STEP 5 storage was limited to approximately $30 \mathrm{~min}$. All groups were compared to non-vitrified controls incubated in BM. In the first three groups, no significant PI dye uptake was observed. By contrast, group 4 undergoing the full procedure showed significant dye uptake (Fig. 5). This suggests that dye uptake and hemichannel opening only occurs when combined with the cooling step, and it is not triggered directly by the other steps of vitrification/ warming protocol.

\section{Vitrification increases TUNEL staining of COCs}

We performed TUNEL staining to study cell death after vitrification in immature COCs (Fig. 1 shows experimental design); this assay mainly tests for apoptosis, but may also be positive for other cell death modes (Kraupp et al. 1995). We found that vitrification significantly increased the percentage of

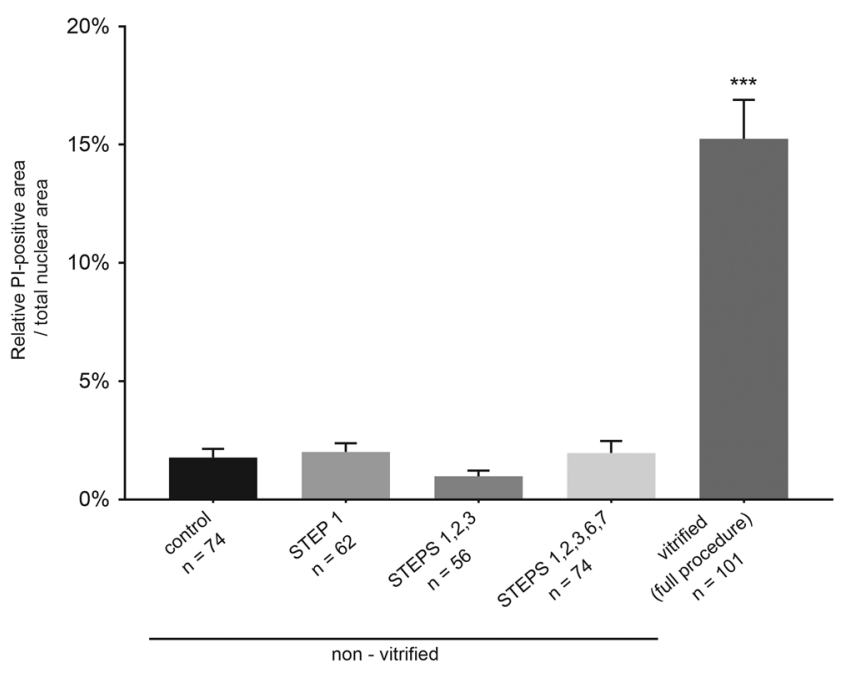

Figure 5 Hemichannel-mediated dye uptake after each step of vitrification process. Dye uptake in COCs was performed after each step of vitrification (equilibration 1 - STEP 1, two equilibration steps 1 and 2 - STEP 1 and 2, equilibration 1 and 2 and loading on a vitrification straw - STEP 1, 2 and 3, two equilibration steps 1 and 2, loading on a straw, warming and wash-out procedure STEP 1, 2, 3, 6 and 7 or full vitrification procedure (includes cooling in $\mathrm{LN}_{2}$ ) vitrified to assess the trigger for hemichannel opening. $\mathrm{HC}$ opening was observed only after full vitrification procedure $\left(\mathrm{LN}_{2}\right.$ cooling and warming)). Exposure to media with a high concentration of CPs, warming from $\mathrm{RT}$ to $39^{\circ} \mathrm{C}$ or mechanical stimulation during handling did not increase $\mathrm{HC}$ opening. The graph shows summary data of the percentage of the PI-positive area relative to the total nuclei (Hoechst) area per COC. Data are presented as mean \pm S.E.M., results were analyzed with a non-parametric ANOVA, Kruskal-Wallis test; ${ }^{* * *} P<0.001$ - difference vs all other groups. 
TUNEL positivity and this was partially inhibited by Gap26. Oocytes were never TUNEL-positive (Fig. 4B). Vitrification thus induces TUNEL positivity without major associated uptake of $10 \mathrm{kDa}$ dextran-FITC dye (always below $0.5 \%$ of the cells), which is in line with the progression of apoptotic cell death, whereby DNA is being fragmented but the plasma membrane stays intact and does not display gross leakage.

\section{Optimization of the vitrification protocol}

Based on the results of PI dye uptake as a proxy for hemichannel opening and TUNEL positivity for cell death/apoptosis we performed a stepwise protocol optimization process. The optimized parameters were (Fig. 2): (i) the equilibration time: the time of the equilibration step before vitrification (Fig. 1, last droplet of STEP 1), (ii) the temperature of the vitrification and warming, (iii) the CPs concentration and (iv) the extracellular $\mathrm{Ca}^{2+}$ concentration.

\section{Equilibration time}

The duration of the equilibration step crucially determines the time for diffusion of the CPs into the tissue and cells. In the PI dye uptake experiments, the equilibration time needed to be prolonged from the standard $10 \mathrm{~min}$ in the primary protocol to $20 \mathrm{~min}$ in order to obtain minimal dye uptake, significantly less compared to the other times tested (Table 1 summarizes the equilibration times tested; Fig. $6 \mathrm{~A}$ shows results). For the TUNEL staining, the equilibration time needed to be further prolonged to $30 \mathrm{~min}$ to minimize the TUNEL signal (Fig. 6B); there, the TUNEL signal became significantly less compared to the other equilibration periods tested. Because the optimal condition was different for dye uptake vs TUNEL assays, we decided to test both conditions further for the other parameters: we assigned them as protocol $\mathrm{A}$ ( 20 min equilibration, minimal dye uptake) and protocol B (30 min equilibration, minimal TUNEL) respectively.

\section{Temperature}

Here, we tested dye uptake and TUNEL staining for both protocol A and B. Interestingly, we noted that the dye uptake responses were slightly different between
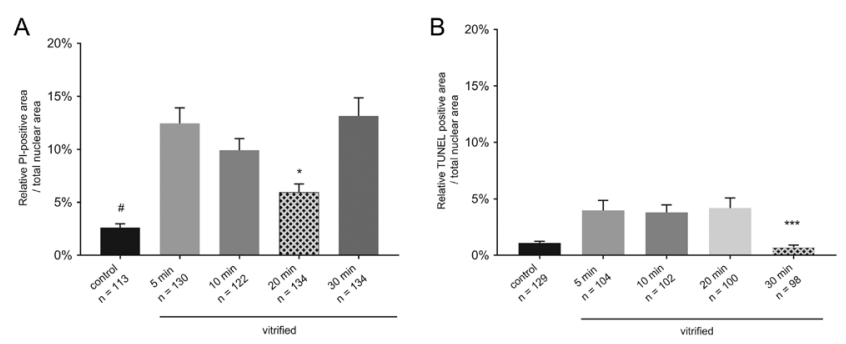

Figure 6 First step of protocol optimization: influence of the equilibration time on the probability of hemichannel opening (A) and apoptotic cell death (B). Testing the duration of the equilibration in the last equilibration drop. (A) 20 min equilibration in the last Equilibration Solution 1 droplet of STEP 2 showed the lowest dye uptake and is further referred as protocol $A$. Oocytes were never PI-positive. ${ }^{\#}$ Difference of control vs vitrified $(P<0.05$ for nonvitrified vs vitrified $20 \mathrm{~min} ; P<0.001$ for non-vitrified vs 5,10 and $30 \mathrm{~min}),{ }^{*}$ difference vs vitrified $20 \mathrm{~min}(P<0.001$ for 20 vs $5 ; P<0.05$ for 20 vs 10 and 20 vs 30); (B) 30 min equilibration in the last droplet of STEP 2 showed the lowest TUNEL positivity and this condition is further referred as protocol B. Oocytes were never TUNEL-positive. The graphs illustrate summary data of the percentage of the PI-positive cell area or TUNEL-positive area relative to the total nuclei (Hoechst) area per COC. ${ }^{* * *}$ Difference of $30 \mathrm{~min}$ condition vs all vitrified groups $P<0.001$. All data are presented as mean \pm S.E.M., results were analyzed with a non-parametric ANOVA, Kruskal-Wallis test.

protocol A and B. In protocol A, PI uptake and TUNEL positivity at $39^{\circ} \mathrm{C}$ were significantly higher compared to all other conditions (Fig. $7 \mathrm{~A}_{1}-\mathrm{A}_{2}$; Table 1 gives temperatures tested). The primary protocol $\mathrm{RT} / 39^{\circ} \mathrm{C}$ condition was not different from the RT condition and, therefore, we kept the primary $\mathrm{RT} / 39^{\circ} \mathrm{C}$ setting. In protocol $\mathrm{B}$, both $\mathrm{RT} / 39^{\circ} \mathrm{C}$ and $39^{\circ} \mathrm{C}$ temperature conditions resulted in significantly higher dye uptake than at RT, so we chose RT here (Fig. $7 \mathrm{~B}_{1}-\mathrm{B}_{2}$ ). TUNEL results were low overall, between 1 and $2 \%$. Therefore, we chose RT as the best compromise for combined low TUNEL/dye uptake scores.

\section{Cryoprotectant concentration}

In protocols $\mathrm{A}$ and $\mathrm{B}$, low $\mathrm{CP}$ concentrations gave the highest dye uptake response. In protocol A, standard and high $\mathrm{CP}$ concentrations were not significantly different, but standard concentrations were slightly lower, so we did not make any changes (Fig. 8A 1 ; Table 1

Table 1 Summary of the protocol conditions.

\begin{tabular}{llll}
\hline Parameter & Primary protocol & Optimized protocol A & Optimized protocol B \\
\hline Equilibration time $^{\mathrm{a}}$ & $10 \mathrm{~min}$ & $20 \mathrm{~min}$ & $30 \mathrm{~min}$ \\
Temperature $^{\mathrm{b}}$ & $\mathrm{RT} / 39^{\circ} \mathrm{C}$ & $\mathrm{RT} / 39^{\circ} \mathrm{C}$ & $\mathrm{RT}$ \\
Cryoprotectant concentration $^{\mathrm{c}}$ & $7.5 \% / 15 \%$ (standard) & $7.5 \% / 15 \%$ (standard) & $10 \% / 20 \%(\mathrm{high})$ \\
Extracellular Ca $^{2+}$ concentration $^{\mathrm{d}}$ & $1.26 \mathrm{mM}$ (normal) & $1.26 \mathrm{mM}$ (normal) & $0.61 \mathrm{mM}(\mathrm{low})$ \\
\hline
\end{tabular}

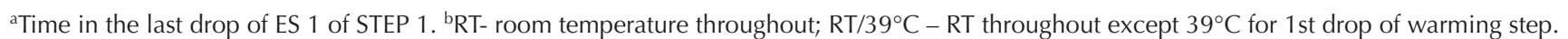
'Standard concentration of the primary protocol: 7.5\% DMSO/7.5\% EG in STEP 1 and 15\% DMSO/15\% EG in STEP 2; High concentration:

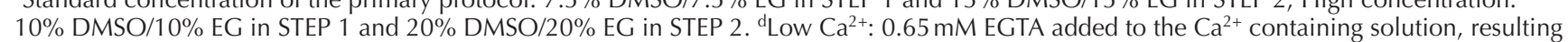
in $0.61 \mathrm{mM}$ free $\mathrm{Ca}^{2+}$; Normal $1.26 \mathrm{mM} \mathrm{Ca}^{2+}$. 

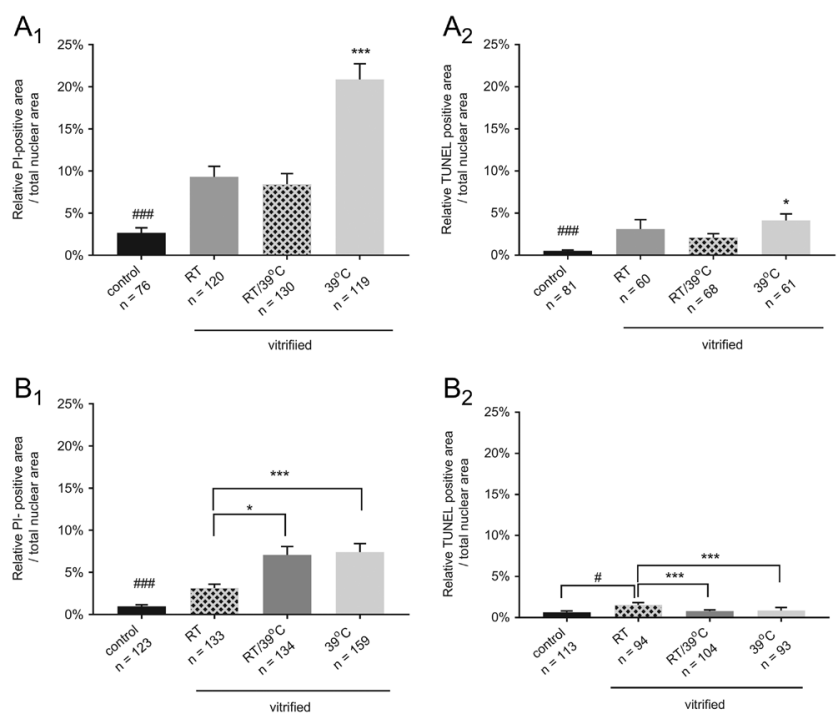

Figure 7 Second step of optimization process: influence of temperature on the probability of hemichannel opening $\left(A_{1}-B_{1}\right)$ and apoptotic cell death $\left(A_{2}-B_{2}\right)$. We tested the response of hemichannels to different vitrification temperature. COCs were vitrified with different optimized protocols (A: $20 \mathrm{~min}$ residence in the last equilibration drop and B: 30 min residence in the last equilibration drop). Best vitrification conditions were chosen based on the results of the previous experiment and are indicated with a pattern for lowest $\mathrm{HC}$ opening and for the lowest apoptosis $\left(A_{1}-A_{2}\right.$ shows results of protocol $A$, and $B_{1}-B_{2}$ shows results of protocol $\left.B\right)$. The graphs illustrate summary data of the percentage of the PI-positive cell area or TUNEL-positive area relative to the total nuclei (Hoechst) area per COC. All data are presented as mean \pm S.E.M., results were analyzed with a non-parametric ANOVA, Kruskal-Wallis test; ${ }^{\# \# P} P<0.001$, ${ }^{\sharp} P<0.05$ difference of control vs vitrified; ${ }^{*} P<0.05,{ }^{* * *} P<0.001$ difference vs other vitrified groups.

gives $\mathrm{CP}$ concentrations tested). In protocol $\mathrm{B}$, high $\mathrm{CP}$ concentrations resulted in considerably less dye uptake than standard concentrations, so we chose to increase the $\mathrm{CP}$ concentration (Fig. $8 \mathrm{~B}_{1}$ ). TUNEL results were very low $(0-1 \%)$ and not significantly different from each other for both $\mathrm{A}$ and $\mathrm{B}$ protocols (Fig. $8 \mathrm{~A}_{2}$ and $\mathrm{B}_{2}$ ).

\section{Extracellular $\mathrm{Ca}^{2+}$ concentration}

Strikingly, changing extracellular $\mathrm{Ca}^{2+}$ gave the most divergent responses for protocols A and B. In protocol A, dye uptake was low (in the order of 1 to $4 \%$ ) reflecting the efficiency of the previous optimization steps. The standard $\mathrm{Ca}^{2+}$ concentration (Table 1) gave the lowest dye uptake which was not different from non-vitrified control (Fig. 9A $\mathrm{A}_{1}$ ). As a result, we did not make any further changes to the protocol. In protocol B, dye uptake was the highest for zero extracellular $\mathrm{Ca}^{2+}$, significantly above the other groups, while low and normal $\mathrm{Ca}^{2+}$ were not different from each other but significantly higher than non-vitrified control (Fig. 9B ${ }_{1}$ ). Because low $\mathrm{Ca}^{2+}$ resulted in the lowest dye uptake, we decided to use this condition for protocol B. As was the case for
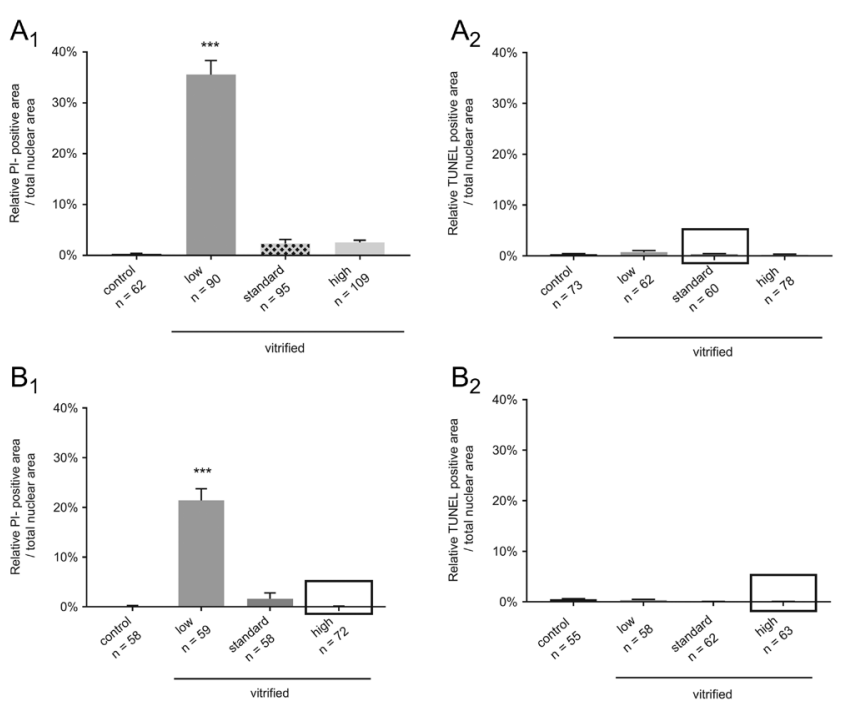

Figure 8 Third step of protocol optimization: influence of the CP concentration (equilibration steps) on the probability of hemichannel opening $\left(A_{1}-B_{1}\right)$ and apoptotic cell death $\left(A_{2}-B_{2}\right)$. COCs were vitrified with different optimized protocols ( $\mathrm{A}$ : $20 \mathrm{~min}$ residence in the last equilibration drop, RT throughout the process except the $39^{\circ} \mathrm{C}$ warming drop and B: 30 min residence in the last equilibration drop and RT throughout the procedure). Best vitrification conditions were chosen based on the results of the previous experiment and are indicated with a pattern or a black box for lowest $\mathrm{HC}$ opening and for the lowest apoptosis $\left(A_{1}-A_{2}\right.$ shows results of protocol $A$, and $B_{1}-B_{2}$ shows results of protocol $B$ ). The graphs illustrate summary data of the percentage of the PI-positive cell area or TUNEL-positive area relative to the total nuclei (Hoechst) area per COC. All data are presented as mean \pm S.E.M., results were analyzed with a nonparametric ANOVA Kruskal-Wallis test; ${ }^{* * * P}<0.001$ in $\mathrm{A}_{1}$ and $\mathrm{B}_{1}$ graph show difference of low $\mathrm{CP}$ concentration vs all other groups.

CP concentration, overall TUNEL results were very low $(0-1 \%)$ reflecting the efficiency of the preceding optimization steps; accordingly, no further protocol adaptions were made. Table 1 concisely summarizes the final optimized parameters for protocols A and B after the four-step procedure explained above; Fig. 9 summarizes the optimized scores for dye uptake and TUNEL staining. Interestingly, protocols $\mathrm{A}$ and $\mathrm{B}$ had comparable final TUNEL scores (protocol A $0.6 \%$; protocol B 2.2\%; statistically not significantly different) while dye uptake in these two conditions were significantly higher in protocol B compared to A (protocol A $0.75 \%$; protocol B 3.45\%; $P<0.0001$ Kruskal-Wallis test with data input of all data bars of Fig. $9 \mathrm{~A}_{1} \& \mathrm{~B}_{1}$ and selected comparison of the two patterned bars).

\section{Effect of optimized vitrification protocols on oocyte maturation and developmental competence}

We tested a control non-vitrified group and three vitrified groups: (i) the primary protocol, (ii) the optimized protocol A and (iii) the optimized protocol B on in vitro maturation and cleavage/development to blastocysts 

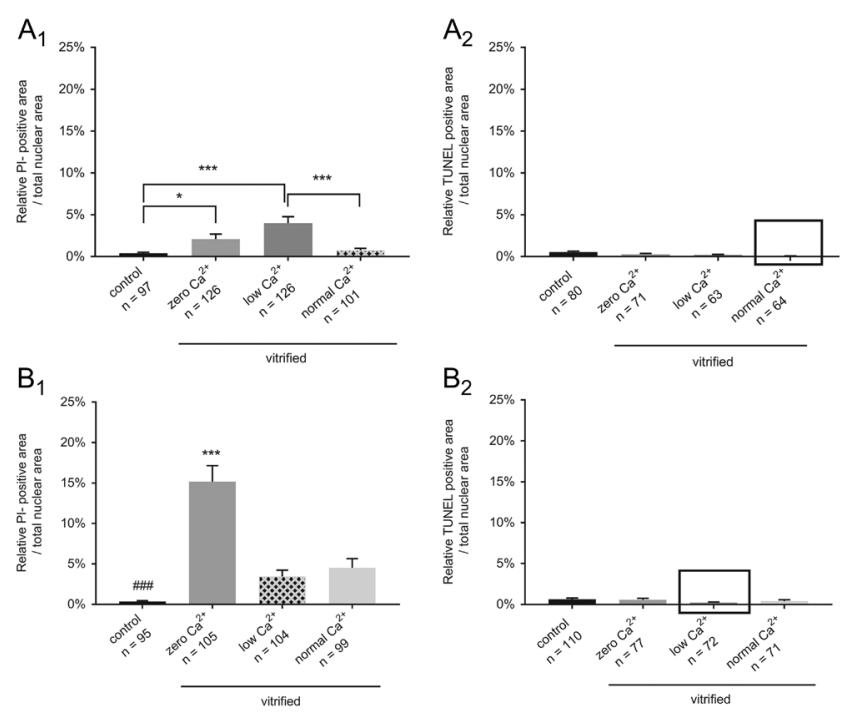

Figure 9 Fourth step of protocol optimization: influence of the extracellular $\mathrm{Ca}^{2+}$ concentration on the probability of hemichannel opening $\left(A_{1}-B_{1}\right)$ and apoptotic cell death $\left(A_{2}-B_{2}\right)$. COCs were vitrified with different optimized protocols and different extracellular $\mathrm{Ca}^{2+}$ concentrations of the media were tested (A: 20 min residence in the last equilibration drop, RT throughout the process except the $39^{\circ} \mathrm{C}$ warming drop, standard CP concentration: $7.5 \% \mathrm{DMSO} / 7.5 \%$ EG in STEP 1 and 15\% DMSO/15\% EG in STEP 2 and B: 30 min residence in the last equilibration drop and RT throughout, high concentration: 10\% DMSO/10\% EG in STEP 1 and 20\% DMSO/20\% EG in STEP 2). Best vitrification conditions were chosen based on the previous results and are indicated with a pattern or a black box for lowest HC opening and for the lowest TUNEL positivity $\left(A_{1}-A_{2}\right.$ shows results of protocol $A$, and $B_{1}-B_{2}$ shows results of protocol $B$ ). The graphs illustrate summary data of the percentage of the PI-positive cell area or TUNEL-positive area relative to the total nuclei (Hoechst) area per COC. All data are presented as mean \pm S.E.M., results were analyzed with a non-parametric ANOVA, Kruskal-Wallis test;

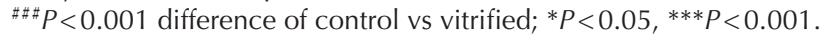

after parthenogenetic activation. Vitrification of GV-stage COCs led to significant reductions in in vitro maturation rates compared to non-vitrified controls (Table 2). No significant differences were detected in the number of oocytes that ceased their development at GV-stage or achieved MII-stage among the vitrified groups. Similarly, the cleavage and blastocyst rates of vitrified COCs were significantly lower than those in the non-vitrified control (Table 3). However, in protocol A, oocytes exhibited significantly higher cleavage rates compared to protocol $B$, but the difference did not attain statistical significance compared to the primary protocol.

\section{Discussion}

Obtaining a vitrified state, in theory, requires optimizing several basic parameters. Unfortunately, species and cell differences preclude creating a standardized protocol that is universally applicable (Elliott et al. 2017). Here, we focused on CXs, in particular hemichannels, as a specific plasma membrane proteins that have potential
Table 2 Effects of optimized protocols on nuclear maturation of vitrified bovine immature COCs.

\begin{tabular}{|c|c|c|c|c|}
\hline & \multirow{2}{*}{$\begin{array}{c}\text { COCs put } \\
\text { in culture, } n\end{array}$} & \multicolumn{3}{|c|}{ Meiotic stage $^{*}(n(\%))$} \\
\hline & & GV & INT & MII \\
\hline Non-vitrified control & 82 & $3(4)^{\mathrm{a}}$ & $13(16)$ & $66(80)^{\mathrm{a}}$ \\
\hline \multicolumn{5}{|l|}{ Vitrified } \\
\hline Primary protocol & 84 & $24(29)^{b}$ & $19(23)$ & $50(60)^{b}$ \\
\hline Optimized protocol A & 84 & $16(19)^{b}$ & $22(26)$ & $48(57)^{\mathrm{b}}$ \\
\hline Optimized protocol B & 82 & $22(27)^{b}$ & $16(20)$ & $44(54)^{b}$ \\
\hline
\end{tabular}

Primary protocol: $10 \mathrm{~min}$ residence in the last equilibration drop, RT throughout the process except the $39^{\circ} \mathrm{C}$ warming drop, standard CP concentration: $7.5 \%$ DMSO/7.5\% EG in STEP 1 and $15 \%$

$\mathrm{DMSO} / 15 \% \mathrm{EG}$, normal $\mathrm{Ca}^{2+}$ concentration: $1.26 \mathrm{mM} \mathrm{Ca}^{2+}$.

Optimized protocol A: 20 min residence in the last equilibration drop, RT throughout the process except the $39^{\circ} \mathrm{C}$ warming drop, standard CP concentration: 7.5\% DMSO/7.5\% EG in STEP 1 and 15\% DMSO/15\% EG, normal $\mathrm{Ca}^{2+}$ concentration: $1.26 \mathrm{mM} \mathrm{Ca}^{2+}$. Optimized protocol B: 30 min residence in the last equilibration drop and RT throughout, high concentration: 10\% DMSO/10\% EG in STEP 1 and 20\% DMSO/20\% EG, low $\mathrm{Ca}^{2+}$ concentration: $0.61 \mathrm{mM} \mathrm{Ca}^{2+}$.

Four replicates were performed and analyzed using binary logistic regression model. Values with different letters in superscripts in the same column are significantly different at $P<0.05$.

GV, germinal vesicle; INT, intermediate, germinal vesicle breakdown (GVBD) or metaphase I (MI); MII, metaphase II.

*26 h of in vitro maturation.

as a target to improve the efficiency of cryopreservation (Bol et al. 2013) and vitrification in particular (OrtizEscribano et al. 2017). The present study shows that vitrification of bovine GV-stage immature COCs results in the opening of hemichannels in the cumulus cells. The trigger for the opening resides in the period of fast cooling/warming and is not caused by osmotic stress or toxicity of CPs. Some studies seem to confirm that

Table 3 Effects of optimized protocols on subsequent cleavage and blastocyst development after parthenogenetic activation of in vitro matured bovine oocytes after being vitrified as immature COCs.

\begin{tabular}{lccc}
\hline & $\begin{array}{c}\text { COCs put in } \\
\text { culture, } \boldsymbol{n}\end{array}$ & $\begin{array}{c}\text { Cleavage, } \\
\boldsymbol{n}(\%)\end{array}$ & $\begin{array}{c}\text { Blastocyst } \\
\text { day } \mathbf{8 , \boldsymbol { n } ( \% )}\end{array}$ \\
\hline $\begin{array}{l}\text { Non-vitrified control } \\
\text { Vitrified* }\end{array}$ & 200 & $178(89)^{\mathrm{a}}$ & $76(38)^{\mathrm{a}}$ \\
$\quad$ Primary protocol & 204 & $123(60)^{\mathrm{b}, \mathrm{c}}$ & $23(11)^{\mathrm{b}}$ \\
$\quad$ Optimized protocol A & 208 & $139(67)^{\mathrm{c}}$ & $22(1)^{\mathrm{b}}$ \\
$\quad$ Optimized protocol B & 199 & $105(53)^{\mathrm{b}}$ & $22(11)^{\mathrm{b}}$ \\
\hline
\end{tabular}

Primary protocol: 10 min residence in the last equilibration drop, RT throughout the process except the $39^{\circ} \mathrm{C}$ warming drop, standard CP concentration: 7.5\% DMSO/7.5\% EG in STEP 1 and 15\% $\mathrm{DMSO} / 15 \% \mathrm{EG}$, normal $\mathrm{Ca}^{2+}$ concentration: $1.26 \mathrm{mM} \mathrm{Ca}^{2+}$. Optimized protocol A: 20 min residence in the last equilibration drop, RT throughout the process except the $39^{\circ} \mathrm{C}$ warming drop, standard CP concentration: 7.5\% DMSO/7.5\% EG in STEP 1 and $15 \%$ DMSO/15\% EG, normal $\mathrm{Ca}^{2+}$ concentration: $1.26 \mathrm{mM} \mathrm{Ca}^{2+}$. Optimized protocol B: 30 min residence in the last equilibration drop and RT throughout, high concentration: 10\% DMSO/10\% EG in STEP 1 and 20\% DMSO/20\% EG, low $\mathrm{Ca}^{2+}$ concentration: $0.61 \mathrm{mM} \mathrm{Ca}^{2+}$. Cleavage was assessed $45 \mathrm{~h}$ after parthenogenetic activation.

Blastocysts were checked at day 8 post activation and represent a percentage per oocyte. Four replicates were performed and analyzed using binary logistic regression model. Values with different letters in superscripts in the same column are significantly different $(P<0.05)$. 
vitrification/warming, and not the exposure to CPs, damages the cumulus cells (Moawad et al. 2013) and has a detrimental effect on further development (Hunter et al. 1995). However, others observed morphological changes in both cases (exposure to CPs and full vitrification procedure) (Hochi et al. 1996).

In the vitrified state, cell signaling is silenced, so hemichannel activation is most likely to take place during the subsequent warming phase. Open hemichannels can, because of their poor molecular and ionic selectivity and high single-channel conductance $(\sim 220 \mathrm{pS}$ for the cumulus-associated CX43), disturb cell function by forming a leakage pore, a process which may further proceed to cell death. Cell death in cumulus cells is known to compromise the viability and developmental potential of the oocyte (Men et al. 2003). Based on this, we aimed to determine optimal cryopreservation conditions that would lead to minimal hemichannel opening and cell death and improved post-vitrification outcomes. The major findings we report here are (i) that hemichannel opening (assessed by dye uptake) as well as cell death (assessed by TUNEL staining) consequent to vitrification can be minimized by adapting critical process parameters, (ii) that dye uptake/hemichannel opening is a sensitive measurement to assess stress conditions occurring in the cumulus cells and (iii) that optimization along protocol A gives a better outcome than along protocol $\mathrm{B}$ as assessed by the cleavage rate after parthenogenetic activation. Below, we discuss these findings in more detail.

We used dye uptake and TUNEL staining to guide the optimization of critical vitrification parameters, such as equilibration time, temperature, $\mathrm{CP}$ concentration and extracellular $\mathrm{Ca}^{2+}$ concentration (Fig. 2). Already in the first optimization step, testing equilibration time, we found that optimization gave a distinct outcome depending on whether the outcome was evaluated by dye uptake or the TUNEL assay. As a result, we distinguished two different protocols, $\mathrm{A}$ and $\mathrm{B}$, that were used throughout the entire optimization procedure (Table 1). In these two protocol arms, optimization was guided by the best compromise between hemichannel opening and cell death scores.

Equilibration time is critical and its prolongation, especially when cryopreserving complex structures like COCs, will secure more time for CP diffusion. Cumulus cells have an influence on CP permeability, with some reporting they may enhance $\mathrm{CP}$ penetration, thereby sheltering the oocyte against rapid osmotic changes (Miyake et al. 1993, Cetin \& Bastan 2006), while others found that cumulus cells hinder CP movement across the oocyte membrane (Brambillasca et al. 2013). In the original protocol (designed for MIl oocytes), equilibration comprises gradual exposure to increasing $\mathrm{CP}$ concentrations to prevent osmotic shock, followed by a 10-min exposure to half the CP concentration. Not surprisingly, our experiments demonstrate that prolonging the equilibration time resulted in less dye uptake and TUNEL positivity: $30 \mathrm{~min}$ was optimal for minimizing the TUNEL readout, while 20 min minimized dye uptake, suggesting that the two assays measure different aspects of cell stress.

The permeability of the plasma membrane to CPs and water depends on the temperature, cell type, developmental stage, and species. At RT, DMSO moves through the oocyte membrane mainly by simple diffusion; for EG, water channels have also been implicated in addition to simple diffusion (Jin et al. 2011). Higher temperature enhances diffusion of CPs (Pegg 2015), but may also favor stress and toxic signaling pathways (Karlsson et al. 2014). In line with the latter, increasing the temperature to $39^{\circ} \mathrm{C}$ (equilibration and warming) resulted in the highest dye uptake and TUNEL signal. The TUNEL assay of protocol B (Fig. $7 \mathrm{~B}_{2}$ ) unexpectedly demonstrated the lowest signal for the $39^{\circ} \mathrm{C}$ condition.

As already referred to, high CP concentrations are needed for successful vitrification and in line with this, we found that low $\mathrm{CP}$ concentrations gave strong dye uptake in protocol $A$ as well as $B$ (Fig. $8 A_{1}$ and $B_{1}$ ). In protocol $B$, the high $C P$ concentration was optimal, probably due to the lower temperature chosen in the previous step, which is expected to decrease CP permeation. Importantly, dye uptake appeared to be a sensitive reporter of low CP-induced cell stress; in contrast, the TUNEL staining was not responding to alterations in $\mathrm{CP}$ concentration suggesting that dye uptake and TUNEL scoring measure distinct cell stress responses.

The effect of different $\mathrm{Ca}^{2+}$ concentrations in the vitrification medium on immature COCs has never been tested before. Excessive entry of $\mathrm{Ca}^{2+}$ into the cell after vitrification, through $\mathrm{Ca}^{2+}$ channels or other less selective pathways including open hemichannels (De Bock et al. 2012, Fiori et al. 2012), may disturb physiological processes and trigger cell death (Decrock et al. 2009b). As a result, lowering extracellular $\mathrm{Ca}^{2+}$ may protect the cells against excessive $\mathrm{Ca}^{2+}$ entry during vitrification (Larman et al. 2006, Succu et al. 2011). Reducing extracellular $\mathrm{Ca}^{2+}$ is, however, not universally protective as lowering extracellular $\mathrm{Ca}^{2+}$ is a well-known trigger for hemichannel opening (Thimm et al. 2005) and the necessity of extracellular $\mathrm{Ca}^{2+}$ and $\mathrm{Mg}^{2+}$ in the medium to prevent oocyte cell injury (Karlsson et al. 2014). In line with this, we found that lowering extracellular $\mathrm{Ca}^{2+}$ to zero significantly promoted hemichannel dye uptake in protocol $\mathrm{B}$. The effect of $\mathrm{Ca}^{2+}$ concentration in the media was negligible in protocol $\mathrm{A}$, as it was already optimized for minimal dye uptake in the first optimization step. When analyzing the various steps of the optimization procedure, it is notable that for the four steps, dye uptake assays showed the strongest responses (see Figs $6 A_{1}, 7 A_{1} \& B_{1}, 8 A_{1} \& B_{1}$ and $9 A_{1} \& B_{1}$ ) while the TUNEL signal was almost undetectable from the third step on (see Figs $8 A_{2} \& B_{2}$ and $9 A_{2} \& B_{2}$ ). Overall, this confirms that dye uptake/hemichannel opening and 
TUNEL positivity indeed measure different aspects of cell stress in the cumulus cells.

After having optimized the conditions of protocols $A$ and $B$, we next tested the impact of this on oocyte maturation and subsequent developmental potential. Most remarkably, regarding maturation, none of the two optimized protocols had any significant effect on the meiotic stages, i.e. GV stage, intermediate stage and MII (Table 2). This is noticeable as it implicates that cumulus cells demonstrating dye uptake or TUNEL positivity have no impact on the progression of nuclear maturation. Interestingly, it has been proposed that vitrification-induced cell death occur in the periphery of the cumulus mass and has therefore little effect on CX communication within the COC (Tharasanit et al. 2009), but others have reported different observations (Hochi et al. 1996, Bogliolo et al. 2007). Nuclear maturation rates were lower in all vitrification groups compared to the non-vitrified condition and various findings have been reported with similar (Ezoe et al. 2015, Tashima et al. 2017), lower (Azari et al. 2017, El-Shalofy et al. 2017) or even higher maturation rates after vitrification (Bulgarelli et al. 2017).

Concerning developmental rates after parthenogenesis, all protocols applied here gave higher cleavage and blastocyst rates than observed by Bulgarelli et al. (2017) and (Ezoe et al. (2015). Interpretation of maturation and developmental results should take into account that we used a closed vitrification system, which reduces the risk of sample contamination at the expense of slightly lower cooling rates. Most interestingly, we found that the cleavage rate after parthenogenetic activation was significantly higher in protocol A as compared to protocol $\mathrm{B}$ (Table 3). To understand the improved cleavage rate in protocol A compared to protocol B, one needs to consider the differences between the two protocols: TUNEL scores were very low and not significantly different, but dye uptake scores were significantly higher in protocol B compared to protocol A and to nonvitrified control. Consequently, the finding that protocol A was better than protocol $B$ in terms of cleavage rates is likely to result from the significantly lower dye uptake in protocol $\mathrm{A}$, that in the final stage was not different from the non-vitrified control. However, we cannot exclude that the unusually long $30 \mathrm{~min}$ equilibration of protocol B (Table 1) is perhaps good for reducing cell death (Fig. 6B) but may have other detrimental side effects that could underlie lower performance of protocol $B$ compared to A.

Comparison of protocol A with the primary protocol did not attain statistical significance, which is remarkable because the primary protocol had significant dye uptake $(\sim 10 \%)$ and TUNEL positivity $(\sim 4 \%)$; yet, it resulted in maturation and developmental scores that are not different from optimized protocol A. This indicates that factors other than hemichannel opening and cell death may play a role. Here as well, the prolonged equilibration time $(20 \mathrm{~min}$ for $\mathrm{A}$ and 30 min for B) may have exerted a negative impact that counteracts the beneficial effects of reducing hemichannel opening and cell death in the cumulus cell mass. Hemichannel opening does not seem to emerge as a major cause of cell death because there was no clear relation between the conditions that reduce hemichannel opening measured by dye uptake and cell death measured by TUNEL staining. This suggests that, in addition to TUNEL and hemichannel assays, other cell stress reporters are needed to fully probe the best conditions and further optimize cryopreservation success.

In conclusion, our work demonstrates that hemichannel dye uptake is a sensitive method to assess cell stress/injury after cryopreservation. Optimizing the vitrification protocol of bovine COCs for minimal dye uptake, as a proxy for hemichannel opening, as well as minimal cell death, resulted in significantly higher cleavage rates after parthenogenetic activation compared to minimization of cell death with remaining hemichannel leakage. However, none of the optimized protocols was better than the original non-optimized protocol indicating that the proposed optimization method needs to be complimented by other cell stress indicators to effectively improve vitrification success in COCs and possibly, in other reproductive cells or tissues expressing CX proteins.

\section{Declaration of interest}

L L holds a patent entitled 'Vessel protect - use of connexin channel inhibitors to protect grafts', PCTEP2013076001, US patent 14/650,553; there are no potential conflicts of interest to disclose.

\section{Funding}

This work was supported in part by the Fund for Scientific Research Flanders (FWO-Vlaanderen), Belgium (grant number G.0A54.13, L L).

\section{Acknowledgement}

The authors gratefully acknowledge Petra Van Damme for her excellent technical assistance.

\section{References}

Ackert CL, Gittens JEI, O'Brien MJ, Eppig JJ \& Kidder GM 2001 Intercellular communication via connexin43 gap junctions is required for ovarian folliculogenesis in the mouse. Developmental Biology 233 258-270. (https://doi.org/10.1006/dbio.2001.0216)

Anderson E \& Albertini DF 1976 Gap junctions between the oocyte and companion follicle cells in the mamalian ovary. Journal of Cell Biology 71 680-686. (https://doi.org/10.1083/jcb.71.2.680)

Arav A 2014 Cryopreservation of oocytes and embryos. Theriogenology 81 96-102. (https://doi.org/10.1016/j.theriogenology.2013.09.011) 
Azari M, Kafi M, Ebrahimi B, Fatehi R \& Jamalzadeh M 2017 Oocyte maturation, embryo development and gene expression following two different methods of bovine cumulus-oocyte complexes vitrification. Veterinary Research Communications 41 49-56. (https://doi.org/10.1007/ s11259-016-9671-8)

De Bock M, Wang N, Bol M, Decrock E, Ponsaerts R, Bultynck G, Dupont G \& Leybaert L 2012 Connexin 43 hemichannels contribute to cytoplasmic $\mathrm{Ca} 2+$ oscillations by providing a bimodal $\mathrm{Ca} 2+-d e p e n d e n t$ Ca2+ entry pathway. Journal of Biological Chemistry 287 12250-12266. (https://doi.org/10.1074/jbc.M111.299610)

Bogliolo L, Ariu F, Fois S, Rosati I, Zedda MT, Leoni G, Succu S, Pau S \& Ledda S 2007 Morphological and biochemical analysis of immature ovine oocytes vitrified with or without cumulus cells. Theriogenology 68 1138-1149. (https://doi.org/10.1016/j.theriogenology.2007.08.013)

Bol M, Van Geyt C, Baert S, Decrock E, Wang N, De Bock M, Gadicherla a K, Randon C, Evans WH, Beele H et al. 2013 Inhibiting connexin channels protects against cryopreservation-induced cell death in human blood vessels. European Journal of Vascular and Endovascular Surgery 45 382-390. (https://doi.org/10.1016/j.ejvs.2012.12.012)

Brambillasca F, Guglielmo MC, Coticchio G, Mignini Renzini M, Dal Canto M \& Fadini R 2013 The current challenges to efficient immature oocyte cryopreservation. Journal of Assisted Reproduction and Genetics 30 1531-1539. (https://doi.org/10.1007/s10815-013-0112-0)

Bulgarelli DL, Vireque AA, Pitangui-Molina CP, Silva-De-Sá MF \& De Sá Rosa-E-Silva ACJ 2017 Reduced competence of immature and mature oocytes vitrified by Cryotop method: assessment by in vitro fertilization and parthenogenetic activation in a bovine model. Zygote 25 222-230. (https://doi.org/10.1017/S0967199416000381)

Cetin Y \& Bastan A 2006 Cryopreservation of immature bovine oocytes by vitrification in straws. Animal Reproduction Science 92 29-36. (https:// doi.org/10.1016/j.anireprosci.2005.05.016)

Contreras JE, Sá Ez JC, Bukauskas FF \& Bennett MVL 2003 Gating and regulation of connexin 43 (Cx43) hemichannels. PNAS 100 11388-11393. (https://doi.org/10.1073/pnas.1434298100)

Decrock E, Vinken M, De Vuyst E, Krysko D V, D'Herde K, Vanhaecke T, Vandenabeele P, Rogiers V \& Leybaert L 2009a Connexin-related signaling in cell death: to live or let die? Cell Death and Differentiation 16 524-536. (https://doi.org/10.1038/cdd.2008.196)

Decrock E, De Vuyst E, Vinken M, Van Moorhem M, Vranckx K, Wang N, Van Laeken L, De Bock M, D'Herde K, Lai CP et al. 2009 b Connexin 43 hemichannels contribute to the propagation of apoptotic cell death in a rat C6 glioma cell model. Cell Death and Differentiation 16 151-163. (https://doi.org/10.1038/cdd.2008.138)

Díez C, Muñoz M, Caamaño JN \& Gómez E 2012 Cryopreservation of the bovine oocyte: current status and perspectives. Reproduction in Domestic Animals 47 76-83. (https://doi.org/10.1111/j.1439-0531.2012.02029.x)

El-Shalofy AS, Moawad AR, Darwish GM, Ismail ST, Badawy ABA \& Badr MR 2017 Effect of different vitrification solutions and cryodevices on viability and subsequent development of buffalo oocytes vitrified at the germinal vesicle (GV) stage. Cryobiology 74 86-92. (https://doi. org/10.1016/j.cryobiol.2016.11.010)

Elliott GD, Wang S \& Fuller BJ 2017 Cryoprotectants: a review of the actions and applications of cryoprotective solutes that modulate cell recovery from ultra-low temperatures. Cryobiology 76 74-91. (https:// doi.org/10.1016/j.cryobiol.2017.04.004)

Evans WH \& Martin PEM 2002 Gap junctions: structure and function (review). Molecular Membrane Biology 19 121-136. (https://doi. org/10.1080/09687680210139839)

Ezoe K, Yabuuchi A, Tani T, Mori C, Miki T, Takayama Y, Beyhan Z, Kato Y, Okuno T, Kobayashi T et al. 2015 Developmental competence of vitrified-warmed bovine oocytes at the germinal-vesicle stage is improved by cyclic adenosine monophosphate modulators during in vitro maturation. PLOS ONE 10 e0126801. (https://doi.org/10.1371/ journal.pone.0126801)

Fiori MC, Figueroa V, Zoghbi ME, Saéz JC, Reuss L \& Altenberg GA 2012 Permeation of calcium through purified connexin 26 hemichannels. Journal of Biological Chemistry 287 40826-40834. (https://doi. org/10.1074/jbc.M112.383281)

Hochi S, Kozawa M, Fujimoto T, Hondo E, Yamada J \& Oguri N 1996 In vitro maturation and transmission electron microscopic observation of horse oocytes after vitrification. Cryobiology 33 300-310. (https://doi. org/10.1006/cryo.1996.0030)
Hunter JE, Fuller BJ, Bernard A, Jackson A \& Shaw RW 1995 Fertilization and early embryology: vitrification of human oocytes following minimal exposure to cryoprotectants; initial studies on fertilization and embryonic development. Human Reproduction 10 1184-1188. (https:// doi.org/10.1093/oxfordjournals.humrep.a136115)

Hwang IS \& Hochi S 2014 Recent progress in cryopreservation of bovine oocytes. BioMed Research International 2014 570647. (https://doi. org/10.1155/2014/625601)

Imoedemhe DG \& Sigue AB 1992 Survival of human oocytes cryopreserved with or without the cumulus in 1,2-propanediol. Journal of Assisted Reproduction and Genetics 9 323-327. (https://doi.org/10.1007/ BF01203954)

Jin B, Kawai Y, Hara T, Takeda S, Seki S, Nakata Y, Matsukawa K, Koshimoto C, Kasai M \& Edashige K 2011 Pathway for the Movement of Water and Cryoprotectants in Bovine Oocytes and Embryos1. Biology of Reproduction 85 834-847. (https://doi.org/10.1095/ biolreprod.110.088641)

Karlsson JOM, Szurek E a, Higgins AZ, Lee SR \& Eroglu A 2014 Optimization of cryoprotectant loading into murine and human oocytes. Cryobiology 68 18-28. (https://doi.org/10.1016/j.cryobiol.2013.11.002)

Kidder GM \& Mhawi AA 2002 Review: gap junctions and ovarian folliculogenesis. Reproduction 123 613-620. (https://doi.org/10.1530/ rep.0.1230613)

Kidder GM \& Vanderhyden BC 2010 Bidirectional communication between oocytes and follicle cells: ensuring oocyte developmental competence. Canadian Journal of Physiology and Pharmacology 88 399-413. (https:// doi.org/10.1139/Y10-009)

Kim Y, Davidson JO, Gunn KC, Phillips AR, Green CR \& Gunn AJ 2016 Role of hemichannels in CNS inflammation and the inflammasome pathway. Advances in Protein Chemistry and Structural Biology 104 1-37. (https://doi.org/10.1016/bs.apcsb.2015.12.001)

Kopeika J, Thornhill A \& Khalaf Y 2015 The effect of cryopreservation on the genome of gametes and embryos: principles of cryobiology and critical appraisal of the evidence. Human Reproduction Update $\mathbf{2 1}$ 209-227. (https://doi.org/10.1093/humupd/dmu063)

Kraupp BG, Ruttkay-Nedecky B, Koudelka H, Bukowska K, Bursch W \& Schulte-Hermann R 1995 In situ detection of fragmented dna (tunel assay) fails to discriminate among apoptosis, necrosis, and autolytic cell death: a cautionary note. Hepatology 21 1465-1468. (https://doi. org/10.1002/hep.1840210534)

Larman MG, Sheehan CB \& Gardner DK 2006 Calcium-free vitrification reduces cryoprotectant-induced zona pellucida hardening and increases fertilization rates in mouse oocytes. Reproduction 131 53-61. (https:// doi.org/10.1530/rep.1.00878)

Li H, Liu T, Peracchia C, Goldberg GS, Lampe PD \& Johnson RG 1996 Properties and regulation of gap junctional hemichannels in the plasma membranes of cultured cells. Journal of Cell Biology 134 1019-1030. (https://doi.org/10.1083/jcb.134.4.1019)

Luciano AM, Chigioni S, Lodde V, Franciosi F, Luvoni GC \& Modina SC 2009 Effect of different cryopreservation protocols on cytoskeleton and gap junction mediated communication integrity in feline germinal vesicle stage oocytes. Cryobiology 59 90-95. (https://doi.org/10.1016/j. cryobiol.2009.05.002)

Men H, Monson RL, Parrish JJ \& Rutledge JJ 2003 Degeneration of cryopreserved bovine oocytes via apoptosis during subsequent culture. Cryobiology 47 73-81. (https://doi.org/10.1016/S00112240(03)00070-1)

Ménézo YJ \& Hérubel F 2002 Mouse and bovine models for human IVF. Reproductive Biomedicine Online 4 170-175. (https://doi.org/10.1016/ S1472-6483(10)61936-0)

Miyake T, Kasai M, Zhu SE, Sakurai T \& Machida T 1993 Vitrification of mouse oocytes and embryos at various stages of development in an ethylene glycol-based solution by a simple method. Theriogenology $\mathbf{4 0}$ 121-134. (https://doi.org/10.1016/0093-691X(93)90346-7)

Moawad AR, Zhu J, Choi I, Amarnath D, Chen W \& Campbell KHS 2013 Production of good-quality blastocyst embryos following IVF of ovine oocytes vitrified at the germinal vesicle stage using a cryoloop. Reproduction, Fertility and Development 25 1204. (https://doi. org/10.1071/RD12215)

Nikseresht M, Toori MA, Rasti T, Kashani IR \& Mahmoudi R 2015 The nuclear maturation and embryo development of mice germinal vesicle oocytes with and without cumulus cell after vitrification. Journal of 
Clinical and Diagnostic Research 9 AF01-AF04. (https://doi.org/10.7860/ JCDR/2015/8856.5421)

Orellana JA, Avendano BC \& Montero TD 2014 Role of connexins and pannexins in ischemic stroke. Current Medicinal Chemistry 21 2165-2182. (https://doi.org/10.2174/0929867321666131228191714)

Ortiz-Escribano N, Smits K, Piepers S, Van den Abbeel E, Woelders H \& Van Soom A 2016 Role of cumulus cells during vitrification and fertilization of mature bovine oocytes: effects on survival, fertilization, and blastocyst development. Theriogenology 86 635-641. (https://doi. org/10.1016/j.theriogenology.2016.02.015)

Ortiz-Escribano N, Szymańska KJ, Bol M, Vandenberghe L, Decrock E, Van Poucke M, Peelman L, Van den Abbeel E, Van Soom A \& Leybaert L 2017 Blocking connexin channels improves embryo development of vitrified bovine blastocysts. Biology of Reproduction 96 288-301. (https://doi.org/10.1095/biolreprod.116.144121)

Pegg DE 2015 Principles of Cryopreservation, pp 3-19. New York, NY: Springer. (https://doi.org/10.1007/978-1-59745-362-2_3)

Puljung MC, Berthoud VM, Beyer EC \& Hanck DA 2004 polyvalent cations constitute the voltage gating particle in human connexin37 hemichannels. Journal of General Physiology 115871700 587-603. (https://doi.org/10.1085/jgp.200409023)

Retamal MA \& Sáez JC 2014 Hemichannels; from the molecule to the function. Frontiers in Physiology 5 411. (https://doi.org/10.3389/ fphys.2014.00411)

Santos RR, Schoevers EJ \& Roelen BAJ 2014 Usefulness of bovine and porcine IVM/IVF models for reproductive toxicology. Reproductive Biology and Endocrinology 12 117. (https://doi.org/10.1186/14777827-12-117)

Simon AM, Goodenough DA, Li E \& Paul DL 1997 Female infertility in mice lacking connexin 37. Nature 385 525-529. (https://doi. org/10.1038/385525a0)

Söhl G \& Willecke K 2003 An update on connexin genes and their nomenclature in mouse and man. Cell Communication and Adhesion 10 173-180. (https://doi.org/10.1080/cac.10.4-6.173.180)

Stoop D, De Munck N, Jansen E, Platteau P, Van den Abbeel E, Verheyen G \& Devroey P 2012 Clinical validation of a closed vitrification system in an oocyte-donation programme. Reproductive Biomedicine Online $\mathbf{2 4}$ 180-185. (https://doi.org/10.1016/j.rbmo.2011.10.015)

Succu S, Berlinguer F, Leoni GG, Bebbere D, Satta V, Marco-Jimenez F, Pasciu V \& Naitana S 2011 Calcium concentration in vitrification medium affects the developmental competence of in vitro matured ovine oocytes. Theriogenology 75 715-721. (https://doi.org/10.1016/j. theriogenology.2010.10.012)

Tashima K, Kubo Y, Hirabayashi M \& Hochi S 2017 Downsizing cumulus cell layers to improve cryotolerance of germinal vesicle-stage bovine oocytes. Theriogenology 95 1-7. (https://doi.org/10.1016/j. theriogenology.2017.02.016)

Tharasanit T, Colleoni S, Galli C, Colenbrander B \& Stout TAE 2009 Protective effects of the cumulus-corona radiata complex during vitrification of horse oocytes. Reproduction 137 391-401. (https://doi. org/10.1530/REP-08-0333)

Thimm J, Mechler A, Lin H, Rhee S \& Lal R 2005 Calcium-dependent open/closed conformations and interfacial energy maps of reconstituted hemichannels. Journal of Biological Chemistry 280 10646-10654. (https://doi.org/10.1074/jbc.M412749200)

VandeVoort CA, Shirley CR, Hill DL \& Leibo SP 2008 Effects of cryoprotectants and cryopreservation on germinal vesicle-stage cumulus-oocyte complexes of rhesus monkeys. Fertility and Sterility $\mathbf{9 0}$ 805-816. (https://doi.org/10.1016/j.fertnstert.2007.06.105)

Veitch GI, Gittens JEI, Shao Q, Laird DW \& Kidder GM 2004 Selective assembly of connexin37 into heterocellular gap junctions at the oocyte/ granulosa cell interface. Journal of Cell Science 117 2699-2707. (https:// doi.org/10.1242/jcs.01124)

Wang H-X, Tong D, El-Gehani F, Tekpetey FR \& Kidder GM 2009 Connexin expression and gap junctional coupling in human cumulus cells: contribution to embryo quality. Journal of Cellular and Molecular Medicine 13 972-984. (https://doi.org/10.1111/j.15824934.2008.00373.x)

Wang N, De Bock M, Decrock E, Bol M, Gadicherla A, Vinken M, Rogiers V, Bukauskas FF, Bultynck G \& Leybaert L 2013 Paracrine signaling through plasma membrane hemichannels. Biochimica et Biophysica Acta - Biomembranes 1828 35-50. (https://doi.org/10.1016/j. bbamem.2012.07.002)

Wydooghe E, Heras S, Dewulf J, Piepers S, Van den Abbeel E, De Sutter P, Vandaele L \& Van Soom A 2014 Replacing serum in culture medium with albumin and insulin, transferrin and selenium is the key to successful bovine embryo development in individual culture. Reproduction, Fertility and Development 26 717. (https://doi. org/10.1071/RD13043)

Yamanaka KI, Aono N, Yoshida H \& Sato E 2007 Cryopreservation and in vitro maturation of germinal vesicle stage oocytes of animals for application in assisted reproductive technology. Reproductive Medicine and Biology 6 61-68. (https://doi.org/10.1111/j.14470578.2007.00167.x)

Zhou XL, Al Naib A, Sun DW \& Lonergan P 2010 Bovine oocyte vitrification using the Cryotop method: effect of cumulus cells and vitrification protocol on survival and subsequent development. Cryobiology $\mathbf{6 1}$ 66-72. (https://doi.org/10.1016/j.cryobiol.2010.05.002)

Received 26 July 2018

First decision 29 August 2018

Revised manuscript received 10 October 2018

Accepted 30 October 2018 